\title{
Ирисы Юго-Восточного Казахстана и перспективы их использования как источников сырья для отечественных фитопрепаратов
}

\section{Irises of southeastern Kazakhstan and the prospects for its use as a source of plant raw materials as domestic herbs}

\author{
Гемеджиева Н. Г., Рамазанова М. С. \\ Gemejiyeva N. G., Ramazanova M. S. \\ Институт ботаники и фитоинтродукции КН МОН РК, г. Алматы, Казахстан. \\ E-mail:ngemed58@mail.ru,r.madin.c@mail.ru
}

Institute of botany and phytointroduction CS MES of the Republic of Kazakhstan, Almaty, Kazakhstan

\begin{abstract}
Peфepam. В статье дан аналитический обзор современного состояния изученности ирисов Юго-Восточного Казахстана из семейства Iridaceae Juss. и показаны перспективы изучения и использования их в качестве источников возобновляемого растительного сырья для получения отечественных фитопрепаратов.
\end{abstract}

Ключевые слова. Ирис, перспективы изучения и использования, Юго-Восточный Казахстан.

Summary. This article provides an analytical review of the current state studies of irises (fam. Iridaceae Juss.) from southeastern Kazakhstan and its prospects for investigation and uses them as a source of sustainable plant raw materials for the production of domestic herbal remedies.

Key words. Iris, prospects for investigation and uses, Southeastern Kazakhstan.

Работа выполнялась в рамках программы: BR05236546 «Реализация Государственными ботаническими садами приоритетных для Казахстана научно-практических задач Глобальной стратегии сохранения растений как устойчивой системы поддержания биоразнообразия» (2018-2020 гг.).

В настоящее время чрезвычайно ценным и незаменимым природным ресурсом выступают лекарственные растения. Современная оценка видового, ресурсного и интродукционного потенциала лекарственной флоры особенно актуальна в условиях Казахстана.

К числу перспективных относятся дикорастущие виды самого многочисленного рода Касатик Iris L. семейства Iridaceae Juss., более известные своими декоративными свойствами. Однако сырье различных видов ириса применялось в кожевенном, красильном, ликеро-водочном производстве, в парфюмерии, в животноводстве, в витаминной, пищевой и текстильной промышленности (Родионенко, 1961). В лекарственных целях использовались ирис бледный (фиалковый корень), флорентийский, германский (I. pallida Lam., I. florentina L., I germanica L.), а также и. тонколистный, и. вильчатый (I. tenuifolia Pall., I. dichotoma Pall.). Следовательно, виды рода Iris L. весьма интересны для комплексного изучения и хозяйственного использования (Растительные ресурсы..., 1994; Дикорастущие полезные..., 2001; Алексеева, 2008; Крюкова и др., 2014). В связи с этим современные ботанические исследования видов p. Iris L. природной флоры Казахстана актуальны и представляют научную и практическую значимость.

Цель исследования - оценка видового разнообразия и изученности полезных свойств видов p. Iris L. Юго-Восточного Казахстана как перспективных источников сырья для создания казахстанских фитопрепаратов.

По разным источникам во флоре Казахстана встречается 19 (22) видов с 3 редкими видами (I. alberti Regel, I. ludwigii Maxim, I. tigridia Bunge), из которых I. ludwigii Maxim, I. alberti Regel являются эндемичными (Флора Казахстана, 1958, 1961; Абдулина, 1999; Байтенов, 2001; Красная книга..., 2014). В народной медицине применяются 8 видов (Аннотированный список..., 2014). 
Большая часть дикорастущих ирисов произрастает на юго-востоке Казахстана в различных экологических условиях, где они встречаются от предгорий и склонов гор Джунгарского Алатау и Северного Тянь-Шаня до пустынной территории Балхаш-Алакольской котловины.

Анализ гербарных материалов (сборов), хранящихся в фонде института, показал, что наибольшее видовое разнообразие ирисов Юго-Восточного Казахстана представлено в Джунгарском (10 видов-I. bloudowii, I. halophila, I. lactea, I. loczyi, I. pallasii, I. ruthenica, I. scariosa, I. sogdiana, I. songarica, I. tenuifolia) и Заилийском, Кунгей Алатау (9 видов-I. alberti, I. bloudowii, I. loczyi, I. pallasii, I. ruthenica, I. scariosa, I. sogdiana, I. songarica, I. tenuifolia). В Балхаш-Алакольском флористическом районе собраны гербарные образцы 6 видов (I. halophila, I. lactea, I. pallasii, I. Sogdiana, I. songarica, I. tenuifolia), в Чу-Илийских горах - 5 видов (I. loczyi, I. scariosa, I. sogdiana, I. songarica, I. tenuifolia), в Кетмень, Терскей Алатау - 4 вида (I. loczyi, I. ruthenica, I. sogdiana, I. songarica).

Литературные данные об ирисах Юго-Восточного Казахстана, обобщенные в таблице, свидетельствует о том, что распространенными являются: I. halophila, встречающийся в 13 флористических районах Казахстана, I. songarica - в 12, I. tenuifolia и I. scariosa - в 11, I. ruthenica - в 10, I. sogdiana - в 8 флористических районах. I. loczyi встречается в 5, a I. lactea и I. bloudowi - в 4 флористических районах Казахстана. I. pallasii - в Джунгарском, Заилийском Алатау (горах Торайгыр) и Балхаш-Алакольском регионе, a I. alberti - эндемик Заилийского Алатау (Голоскоков, 1984; Растения природной ..., 1990; Растительные ресурсы..., 1994; Дикорастущие полезные..., 2001; Коллекционные фонды..., 2015).

Местообитания ирисов Юго-Восточного Казахстана приурочены преимущественно к степной зоне (I. halophila, I. ruthenica, I.scariosa, I. songarica, I. tenuifolia) и солончаковым, солонцеватым лугам (I. halophila, I. pallasii, I. lactea, I. scariosa). По три вида встречаются в долинах озер и речек, по берегам речек (I. halophila, I. lactea, I. sogdiana) и горным склонам (I. bloudowii, I. loczyi, I. ruthenica), по 2 вида - на каменистых, щебнистых склонах гор (I. scariosa, I. songarica) и разнотравных склонах предгорий (I. alberti, I. songarica). К видам с узкой экологической приуроченностью местообитаний относятся I. tenuifolia (глинистые и супесчаные пустыни), и I. sogdiana (травянистые болота, сырые берега рек) (таблица).

Из 11 ирисов Юго-Восточного Казахстана лекарственными и декоративными свойствами характеризуются 6 видов (I. alberti, I. lactea, I. ruthenica, I. sogdiana, I. songarica, I. tenuifolia), из которых I. ruthenica известен также как медоносное и кормовое растение, а I. songarica-ядовит.

В качестве лекарственного сырья применяют все растение или подземную часть, которые содержат эфирное масло, изофлавоноиды, флавоноиды, каротиноиды, различные органические кислоты и дубильные вещества. Корневища некоторых ирисов оказывают иммуномодулирующее, противовоспалительное, тонизирующее действие (Дикорастущие полезные ..., 2001). У ирисов Юго-Восточного Казахстана в подземной части выявлены также кумарины, витамин С, углеводы и родственные соединения; в надземной - фенолкарбоновые кислоты и их производные, ксантоны. Применяемые в народной $(\mathrm{HM})$, восточной (BM) и экспериментальной медицине (ЭМ) ирисы юго-востока Казахстана характеризуются антигельминтными, ранозаживляющими, вяжущими, противовоспалительными, антивирусными, диуретическими и другими свойствами (Аннотированный список..., 2014). Для 4 видов данные по химическому составу и полезным свойствам отсутствуют (таблица).

Некоторые дикорастущие виды ириса (I. alberti, I. pallasii, I. ruthenica, I. scariosa) образуют почти чистые заросли площадью до нескольких сотен квадратных метров (Иващенко, 2008), поэтому актуальны ресурсные исследования их природных популяций. Обзор интродукционной изученности ирисов показал, что большая часть казахстанских видов была испытана в культуре в: Главном ботаническом саду (ГБС) - 13 видов, Алтайском ботсаду (АВС) - 4 (I. alberti, I. bloudowii, I. humilis, I. ruthenica), Карагандинском ботсаду (КБС) - 3 (I. alberti, I. pumila, I. sibirica), Джезказганском ботсаду (ДБС) - 2 (I. pumila, I. sibirica). Более изучены 8 видов ирисов Юго-Восточного Казахстана (I. alberti, I. bloudowii, I. halophila, I. loczyi, I. ruthenica, I. scariosa, I. sogdiana, I. songarica), привлеченные преимущественно из природных местообитаний хребта Заилийский Алатау (Растения природной ..., 1990; Коллекционные фонды..., 2015; Мухитдинов и др., 2015; Съедина, Отрадных..., 2016). Не испытывались в культуре I. pallasii, I. lactea, I. tenuifolia. 


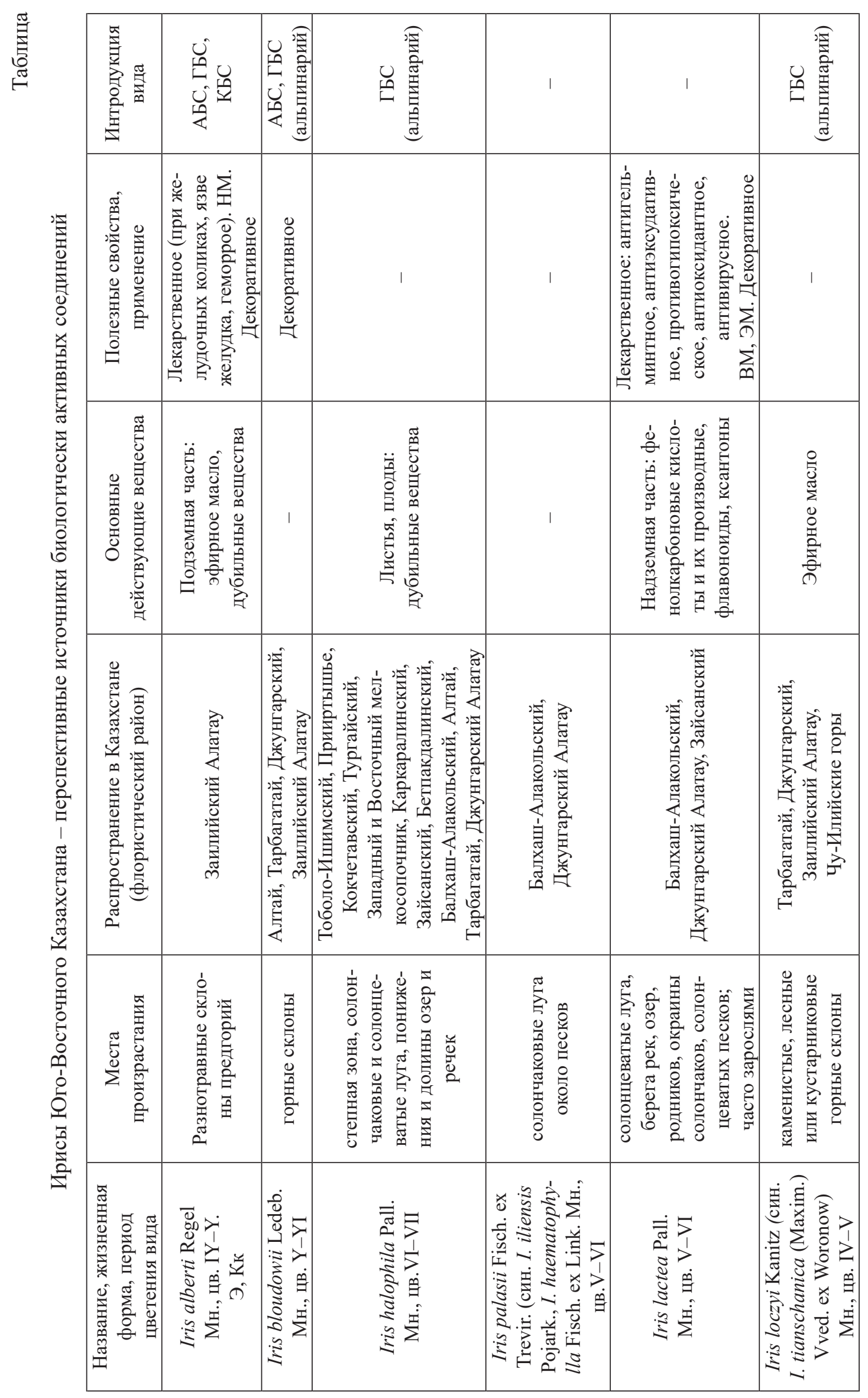




\begin{tabular}{|c|c|c|c|c|c|}
\hline 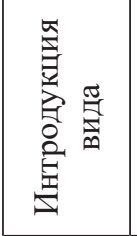 & 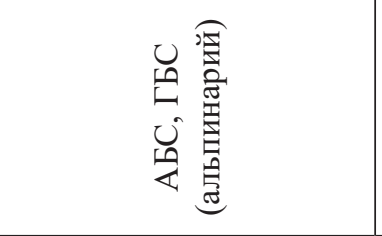 & 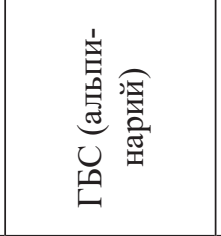 & 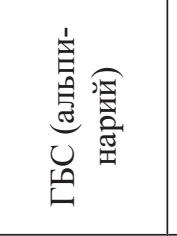 & 苡 & ' \\
\hline 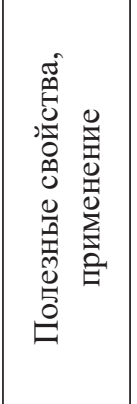 & 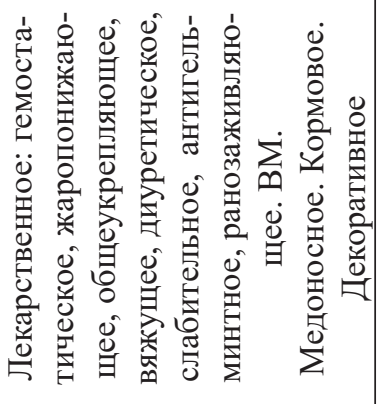 & 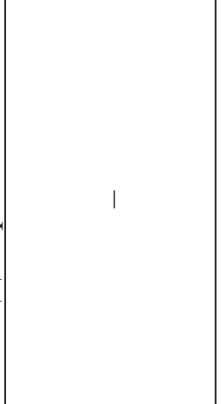 & 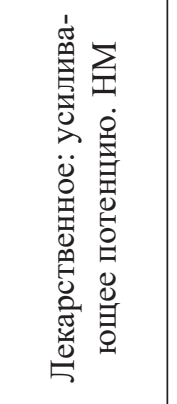 & 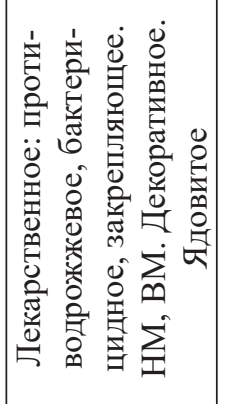 & 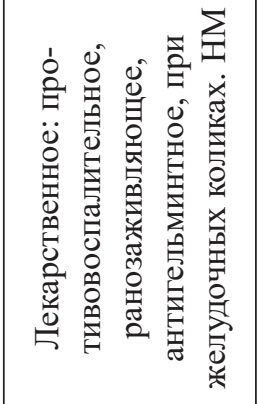 \\
\hline 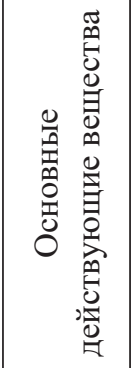 & 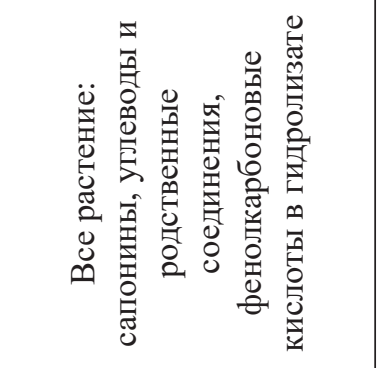 & 1 & 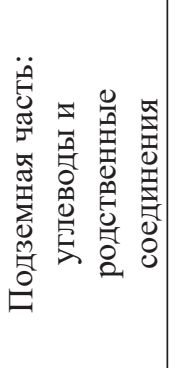 & 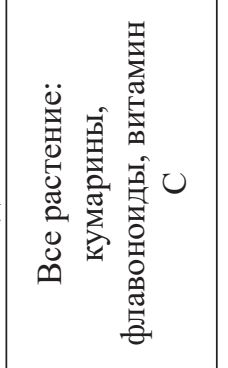 & 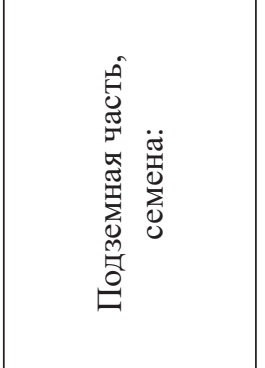 \\
\hline 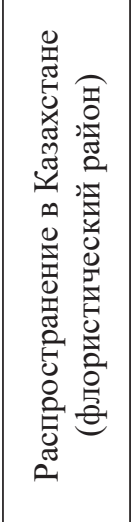 & 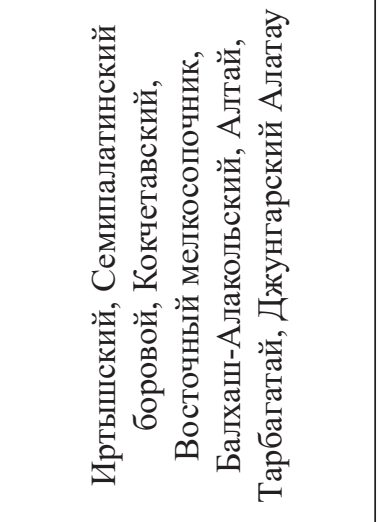 & 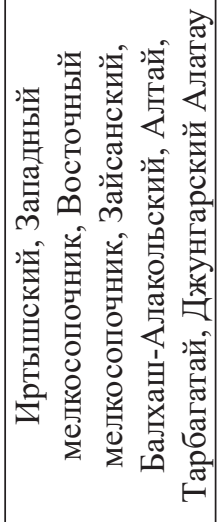 & 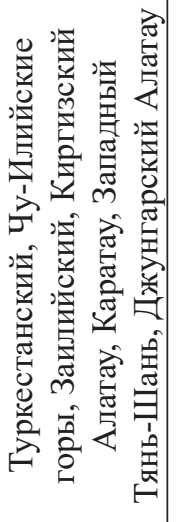 & 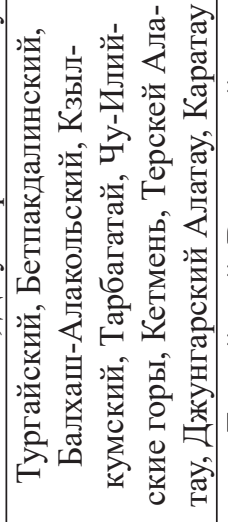 & 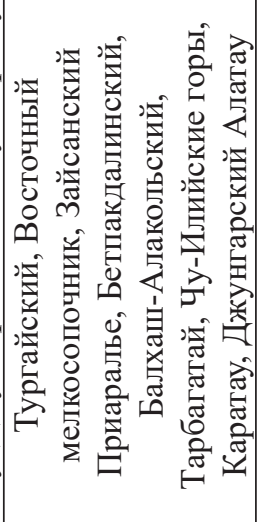 \\
\hline 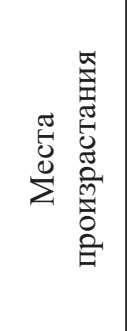 & 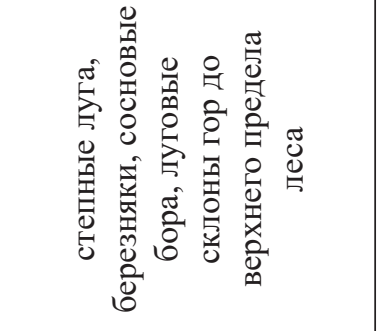 & 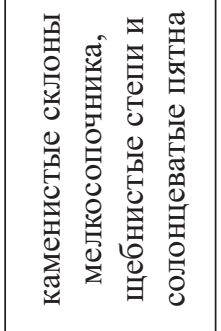 & 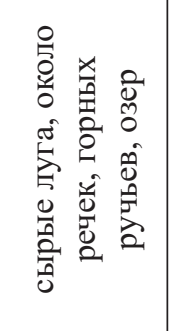 & 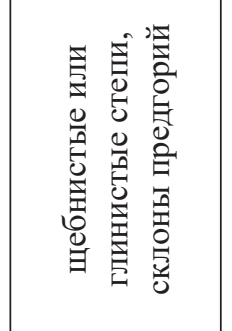 & 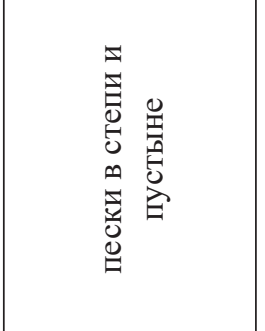 \\
\hline 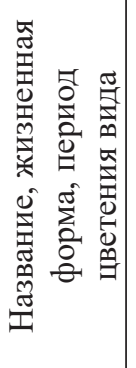 & 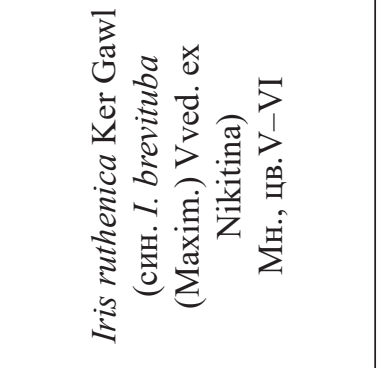 & 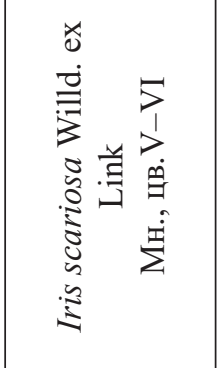 & 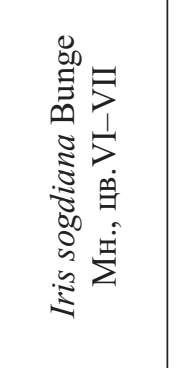 & 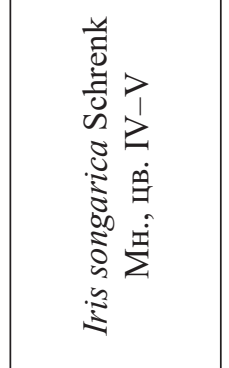 & 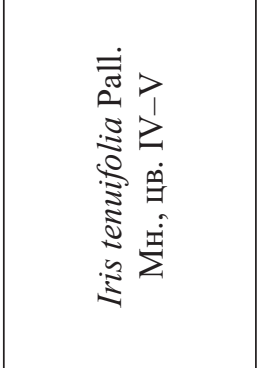 \\
\hline
\end{tabular}


Таким образом, ирисы Юго-Восточного Казахстана, характеризующиеся видовым разнообразием и разносторонним спектром полезных свойств, перспективны для комплексного изучения и использования их в качестве источников возобновляемого растительного сырья для получения отечественных фитопрепаратов.

\section{ЛИТЕРАТУРА}

Абдулина C. A. Список сосудистых растений Казахстана / под редакцией Р. В. Камелина. - Алматы, 1999. - С. 106-107.

Алексеева Н. Б. Род Iris L. (Iridaceae) в России // Turczaninowia, 2008. - Т. 11. № 2. - С. 5-68.

Аннотированный список лекарственных растений Казахстана: Справочное издание / Л. М. Грудзинская, Н. Г. Гемеджиева, Н. В. Нелина, Ж. Ж. Каржаубекова. - Алматы, 2014. - С. 86-87.

Байтенов М. С. Флора Казахстана. Т. 2. Родовой комплекс флоры. - Алматы: Ғылым, 2001. - С. 54.

Голоскоков В.П. Флора Джунгарского Алатау (конспект и анализ). - Алма-Ата: Наука, 1984. - С. 43-44.

Дикорастущие полезные растения России / Отв. ред. Буданцев А. Л., Лесиовская Е. Е. - СПб.: Издательство СПХФА, 2001. - С. 320.

Иващенко $\boldsymbol{A}$. A. Цветковые растения юго-востока Казахстана: полевой определитель наиболее распространенных видов. - Алматы: Ассоциация сохранения биоразнообразия Казахстана, 2008. - 184 с.

Коллекционные фонды Главного ботанического сада ИБФ КН МОН РК // Вестник Совета ботанических садов Казахстана. - Вып. 3. - Алматы, 2015. - С.70-72.

Красная книга Казахстана. Изд. 2-е, переработанное и дополненное. - Том 2: Растения (колл. авторов). Астана, ТОО «АртPrintXXI», 2014. - С. 335-337.

Крюкова А. В., Абрамова Л. М., Мустафина А. Н. Редкие степные виды рода Iris L. в Республике Башкортостан // Степи Северной Евразии: мат. VIII междунар. симп. /под научной редакцией академика РАН А. А. Чибилёва. - Оренбург: ИС УрО РАН, 2018. - С. 521-523.

Мухитдинов Н., Аметов А., Абидкулова К. Т. Характеристика растительных сообществ с участием редкого, эндемичного и лекарственного растения Iris alberti Regel (Большое Алматинское ущелье Заилийского Алатау) // Вестник КазНУ. Серия экологическая, 2015. - Т. 45. №3. - С. 226-231.

Растительные ресурсы России и сопредельных государств: Цветковые растения, их химический состав, использование. Семейства Butonaceae-Typhaceae. - СПб.: Наука, 1994, - С. 77-82.

Растения природной флоры Казахстана в интродукции. Справочник. - Алма-Ата: Гылым, 1990. - 287 с.

Родионенко Г. И. Род Ирис - Iris L. - М.-Л., 1961. - 216 с.

Съедина И. А., Отрадных И. Г. Феноритмы редких декоративных травянистых растений Северного Тянь-Шаня в Альпинарии ботанического сада Алматы // Сохранение разнообразия растительного мира в ботанических садах: традиции, современность, перспективы: мат. Междунар. конф., посвященной 70-летию ЦСБС (г. Новосибирск, 1-8 августа 2016). - Новосибирск, 2016. - С. 288-289.

Флора Казахстана. - Алма-Ата, 1958. - Т. 2. - С. 233-246;. - 1961. - Т. 5.- С. 496-497. 